\title{
Stem Cell - The Future Little Master in Dentistry
}

\author{
Md. Nazmul Hasan ${ }^{a}$, Mehmet Ali Darendeliler $^{b}$
}

Dental exfoliations in human during childhood or in adulthood, whatever the reason might be, could only be replaced with conventional prosthesis at present date. However, progress in stem cell biology and tissue engineering may present new options for replacing heavily damaged or lost teeth, or even individual tooth structures. The promise of such treatment possibilities puts stem cells in the focus of dental research. Stem cells are primitive cells found in all multi-cellular organisms that are characterized by self-renewal and the capacity to differentiate into any mature cell type. These stem cells have the awesome potential for regeneration and may be used to replace or repair damaged cells. They have the potential to drastically change the treatment of conditions like cancer, Alzheimer's and Parkinson's disease and even paralysis ${ }^{1}$. Stem cells are defined as having the capacity for extensive self-renewal and for originating at least one type of highly differentiated descendant ${ }^{2}$. There are 2 main types of stem cells - embryonic stem cells and adult stem cells - which are classified according to their origin and differentiation potential ${ }^{3}$.

The embryonic stem cells are pluripotent, that is, they can differentiate into all types of somatic cells and theoretically divide an unlimited number of times ${ }^{4}$.Adult stem cells, mostly multipotent, are theoretically present in every type of tissue. Organs that are particularly suited for yielding adult stem cells include the bone marrow,the umbilical cord, and umbilical cord blood $^{5}$.The primary roles of adult stem cells in a living organism are to maintain and repair the tissue in which they are found. In a living animal adult stem cell, can divide for a long period and can give rise to mature cell types that have characteristic shapes and specialized structures and functions of a particular tissue like neural cells, cardiac muscles etc. Possibly the best- known stem cell therapy to date is the bone marrow transplant, which is used to treat leukemia and other types of cancer, as well as various blood disorders.

Adult dental ectomesenchymal stem cells seem promising for future therapy. Human stem cells have been isolated from the dental pulp, exfoliated deciduous teeth, the periodontal ligament, the dental follicle and the dental papilla ${ }^{5}$.In humans, odontogenesis begins in about the $10^{\text {th }}$ week of intrauterine life.Wisdom teeth develop post-natally; their enamel organ has formed by about the $72^{\text {nd }}$ month of life.This means that up to that point, undifferentiated dental embryonic tissue exists in the jaw. The development of the third molars is the only organogenesis which takes place completely after birth.The basis for the regeneration of teeth or individual dental tissues is the acquisition of suitable stem cells and a suitable environment in which these cells can differentiate into the target tissues.

Unlike human teeth, the incisors of rodents grow throughout the animal's life. A source of epithelial stem cells, the apical bud cells ( $\mathrm{ABCs}$ ), in the apical epithelium is responsible for continuous enamel production. In human with the exception of ameloblast progenitor cells, all stem cells involved in odontogenesis originate in mesenchyme. Therefore, besides in other fields of medicine, mesenchymal stem cells can play an important role in the field of dentistry as it could help in regeneration of vital structures like bone, cementum, periodontal ligament fibers, and dental pulp.

Several craniofacial structures-such as the mandibular condyle, calvarial bone, cranial suture, and subcutaneous adipose tissue-have been engineered from mesenchymal stem cells, growth factor, and/or gene therapy approaches. Adult mesenchymal stem cells have advantages over embryonic stem cells for tissue engineering 
of the mandibular condyle, because adult mesenchymal stem cells can be obtained from the same individual and readily induced to differentiate into both chondrogenic and osteogenic cells ${ }^{6}$. Bio-engineered teeth can be derived from cultured tooth bud cells. Deciduous teeth contain a population of more immature multipotent stem cells, which are capable of forming dentin-like structures but not a complete dentin-pulp complex. The developed bioengineered tooth had a well-defined pulp chambers, odontoblasts, pre-dentin, and dentin. It also contained a morphologically correct enamel organ consisting of stellate reticulum, stratum intermedium, ameloblasts, and dental enamel. In addition, putative Hertwig's root sheath epithelia were also present ${ }^{7,8}$.Dental pulp stem cells were capable of generating a reparative dentin-like structure directly on the surface of human dentin", which could be highly beneficial in operative dentistry practice. Periodontal tissue repair is also possible by 'gene-enhanced periodontal regeneration' technique ${ }^{10}$ and 'regenerative endodontic procedure' has also been proposed with mesenchymal stem cells tissue engineering. Repair of orthodontic root resorption and accelerated orthodontic tooth movement could also be performed with this engineering aid.

Thus the concept starts with prosthetic replacement, now opens its new horizon of prospect in the oasis of advance clinical dentistry and has the potential to master the future dentistry, which is the little stem cell.

\section{Md. Nazmul Hasan ${ }^{a}$, Mehmet Ali Darendeliler ${ }^{b}$}

a. Assistant Professor and Head, Department of Orthodontics \& Dentofacial Orthopedics, Update Dental College \& Hospital, Dhaka, Bangladesh.

b. Professor and Head, Discipline of Orthodontics, Faculty of Dentistry, University of Sydney, Sydney, Australia.

\section{References:}

1. Rosenthal N. Prometheus's vulture and the stem-cell promise. N Engl J Med 2003;349:267-74.

2. Becker AJ, McCulloch EA, Till JE. Cytological demonstration of the clonal nature of spleen colonies derived from transplanted mouse marrow cells. Nature 1963;197:4524

3. Giordano A, Galderisi U, Marino IR. From the laboratory bench to the patient's bedside: An update on clinical trials with mesenchymal stem cells. J Cell Physiol 2007; 211:27-35

4. Morsczeck C, Reichert T E, Vollner F, Gerlach T, Driemel O. The state of the art in human dental stem cell research. Mund Kiefer Gesichts-chir 2007;11:259-266.

5. Ulmer FL, Winkel $A$, Kohorst $P$, Stiesch $M$. Stem Cells- Prospect in Dentistry. Schweiz Monatsschr Zahnmed 2010;120(10):860-83.
6. Agata $H$, Asahina I, Yamazaki $Y$, Uchida $M$, Shinohara Y, Honda MJ, et al. Experimented on periosteum-derived cells in-effective bone engineering with periosteum-derived cells. J Dent Res 2007;86:79-83.

7. Cheng $\mathrm{PH}$, Snyder B, Fillos D, Ibegbu CC, Huang $\mathrm{AH}$, Chan AW. Postnatal stem/progenitor cells derived from the dental pulp of adult chimpanzee. BMC Cell Biol 2008;9:20

8. Batouli S, Miura M, Brahim J, Tsutsui TW, Fisher LW, Gronthos S, et al. Comparison of stem-cell-mediated osteogenesis and dentinogenesis J Dent Res 2003;82:976-81.

9. Chang J, Zhang C, Tani-Ishii N, Shi S, Wang CY. NF-kB Activation in human dental pulp stem cells by TNF and LPS. J Dent Res 2005;84:994-8

10. Goldberg $M$, Smith AJ. Cells and extracellular matrices of dentin and pulp: A biological basis for repair and tissue engineering. Crit Rev Oral Biol Med 2004;15:13-27. 
